\title{
A phase 2 study of temozolomide in pretreated metastatic colorectal cancer with MGMT promoter methylation
}

\author{
M A Calegari ${ }^{\star 1,1,6}$, A Inno ${ }^{2,6}$, S Monterisi $^{1}$, A Orlandi ${ }^{1}$, D Santini ${ }^{3}$, M Basso ${ }^{1}$, A Cassano ${ }^{1}$, M Martini ${ }^{4}$, T Cenci $^{4}$, \\ I de Pascalis ${ }^{4}$, F Camarda ${ }^{1}$, B Barbaro ${ }^{5}$, L M Larocca ${ }^{4}$, S Gori ${ }^{2}$, G Tonini ${ }^{3}$ and C Barone ${ }^{1}$ \\ ${ }^{1}$ Division of Medical Oncology, Catholic University of the Sacred Heart, Largo Agostino Gemelli, 8, Rome 00168, Italy; ${ }^{2}$ Medical \\ Oncology Unit, 'Sacro Cuore Don Calabria' Hospital Cancer Care Center, Verona 37024, Italy; ${ }^{3}$ Division of Medical Oncology, \\ Campus Bio-medico University, Rome 00128, Italy; Institute of Pathological Anatomy, Catholic University of the Sacred Heart, \\ Rome 00168, Italy and ${ }^{5}$ Institute of Radiology, Catholic University of the Sacred Heart, Rome 00168, Italy
}

Background: Presently, few options are available for refractory colorectal cancer (CRC). O6-methyl-guanine-DNA-methyltransferase (MGMT) promoter methylation is a frequent and early event in CRC tumourigenesis. This epigenetic silencing is a predictor of response to the alkylating drug temozolomide in glioblastoma. Preclinical evidences and some case reports showed temozolomide activity in CRC with MGMT silencing, but the available data from clinical trials are inconsistent.

Methods: This was a multicentre, phase 2 trial, planned according to a two-stage Simon's optimal design to investigate activity and safety of temozolomide in refractory CRC harbouring MGMT promoter methylation. The primary end point was overall response rate (ORR). Patients who failed two or more prior treatments received temozolomide at a dose of $150-200 \mathrm{mg} \mathrm{m}^{-2}$ per day on days $1-5$ every 28 days.

Results: From July 2012 to June 2016, 225 patients were screened, 80 showed MGMT promoter methylation and 41 were enrolled. Overall response rate was $10 \%$ and disease control rate was 32\%. Median progression-free survival and overall survival were 1.9 and 5.1 months, respectively.

Conclusions: Temozolomide showed a modest activity in this heavily pretreated population and the study did not meet its primary end point. The role of temozolomide in CRC remains still controversial and further research is warranted.

Worldwide, colorectal cancer (CRC) is the third most commonly diagnosed malignancy and one of the leading causes of cancerrelated deaths, with an estimated 1.4 million cases and 693900 deaths occurring in 2012 (Torre et al, 2015). Around 25\% of patients present with metastatic disease at diagnosis and at least $50 \%$ of those with early disease eventually develop metastases (Van Cutsem et al, 2010). Historically, for patients with unresectable metastatic CRC (mCRC) the only available systemic treatment was chemotherapy, including fluoropyrimidines, oxaliplatin and irinotecan, with a median overall survival (mOS) of $\sim 20$ months (Tournigand et al, 2004). Over the past decade, the introduction of anti-EGFR antibodies (cetuximab and panitumumab) for patients with RAS wild-type (WT) tumours (Douillard et al, 2014; Van Cutsem et al, 2015) and antiangiogenic agents (bevacizumab, aflibercept and ramucirumab) has significantly improved the outcome (Slatz et al, 2008; Van Cutsem et al, 2012; Tabernero et al, 2015), extending mOS to almost 30 months (Cremolini et al, 2015). More recently, the multikinase inhibitor regorafenib

^Correspondence: Dr MA Calegari; E-mail: mariaalessandra.calegari@gmail.com

${ }^{6}$ These authors contributed equally to this work.

Received 6 December 2016; revised 19 February 2017; accepted 28 March 2017; published online 20 April 2017

(C) 2017 Cancer Research UK. All rights reserved 0007 - 0920/17 
(Grothey et al, 2013) and the novel oral fluoropyrimidine TAS-102 (Mayer et al, 2015) have demonstrated efficacy in refractory patients.

Despite such advances, prognosis of patients failing standard therapies remains poor. However, many refractory patients still maintain a good performance status (PS) and are potentially suitable for further active treatment. Therefore, the development of novel approaches for pretreated mCRC patients represents an unmet clinical need.

Temozolomide (TMZ) is an oral alkylating agent with a broad spectrum of antitumour activity. It is indicated for the treatment of patients with glioblastoma (Stupp et al, 2005, 2009), and widely used in patients with refractory metastatic melanoma (Middleton et al, 2000; Patel et al, 2011) and advanced pancreatic neuroendocrine tumours (Chan et al, 2012). Its antitumour activity relies on methylation of DNA at the O6 position of guanine, which leads to DNA double-strand breaks and subsequent DNA replication inhibition and apoptosis (Newlands et al, 1997). The predominant mechanism of resistance to TMZ is the expression of O6-methylguanine-DNA-methyltransferase (MGMT), a DNA repair enzyme that removes the O6-methyl-guanine DNA adducts in a one-step suicide reaction (Pegg, 1990; van Nifterik et al, 2010). O6-methylguanine-DNA-methyltransferase levels are regulated through an epigenetic mechanism (Heigi et al, 2005). Indeed, methylation of the $\mathrm{CpG}$ dinucleotides in the promoter region leads to a transcriptional silencing, thus causing a failure to repair the TMZ-induced DNA damage (Esteller and Herman, 2004). Both MGMT methylation and the absence of MGMT protein have been associated with in vitro sensitivity to TMZ in different human tumour cell lines. Moreover, MGMT methylation has been identified as a prognostic factor and a predictor of response to TMZ in glioblastoma (Hegi et al, 2005; Dunn et al, 2009).

O6-methyl-guanine-DNA-methyltransferase methylation represents a quite frequent as well as relevant event in colorectal cancerogenesis. About $27-40 \%$ of mCRC present a low expression of MGMT protein due to gene promoter methylation (Esteller and Herman, 2004), with higher prevalence among CRC with KRAS mutation (Esteller et al, 2000). In fact, in a series of 244 CRC, MGMT methylation was found in $71 \%$ of tumours with KRAS $\mathrm{G}>\mathrm{A}$ mutations, in $32 \%$ of those with non-G $>\mathrm{A} K R A S$ mutations and in $35 \%$ of WT KRAS tumours. Temozolomide showed in vitro activity against a large variety of human tumour cell lines, including colorectal cancer (Raymond et al, 1997). In 2011, Shacham-Shmueli et al (2011) reported two cases of impressive clinical response to TMZ in patients with MGMT loss of expression. This evidence provided the rationale for investigating TMZ in mCRC. Four mono-institutional, phase 2 trials have been published so far with different results (Hochhauser et al, 2013; Pietrantonio et al, 2014, 2016; Amatu et al, 2016). Here, we report the results of a multicentre phase 2 trial assessing activity and safety of TMZ in refractory patients with mCRC.

\section{PATIENTS AND METHODS}

Study population. Patients with histologically confirmed mCRC harbouring MGMT promoter methylation were eligible for inclusion if they met all of the following criteria: age $\geqslant 18$ years; Eastern Cooperative Oncology Group (ECOG) PS $\leqslant 2$; life expectancy of at least 3 months; at least one measurable lesion as defined by Response Evaluation Criteria in Solid Tumours (RECIST) v.1.1; failure of at least two previous chemotherapy regimens (including fluoropyrimidines, irinotecan, oxaliplatin, bevacizumab and, if RAS WT, an anti-EGFR antibody); radiological progressive disease (PD) during or within 6 months from the end of the previous treatment or unacceptable toxicity to the previous treatment; adequate hepatic, renal and bone marrow function (defined as white blood cell count $\geqslant 3 \times 10^{9} / 1$ with absolute neutrophil count (ANC) $\geqslant 1.5 \times 10^{9} / 1$, platelet count $\geqslant 100 \times 10^{9} / 1$ and haemoglobin $>9 \mathrm{~g} \mathrm{dl}^{-1}$; total serum bilirubin $<1.5$ times upper limit of normal (ULN), unless documented Gilbert's syndrome; ALT $\leqslant 2.5 \times \mathrm{ULN}$ or $\leqslant 5 \times \mathrm{ULN}$ in patients with liver metastases; serum creatinine $\leqslant 1.5 \times$ ULN or calculated creatinine clearance $\geqslant 50 \mathrm{ml} \mathrm{min}^{-1}$ according to Crockcroft and Gault; INR and aPTT $\leqslant 1.5 \times \mathrm{ULN}$, unless on therapeutic anticoagulation). Patients were ineligible if they met any of the following exclusion criteria: history of any other severe or uncontrolled disease; pregnancy or lactation; existing acute effects of prior treatment; history of any other malignancy within the previous 5 years, except for patients appropriately treated for skin carcinoma (other than melanoma) or in situ cervical carcinoma, or those treated with curative intent for any other cancer with no evidence of disease for at least 5 years. The presence of MGMT promoter methylation was assessed by methylation-specific polymerase chain reaction (MS-PCR), the evaluation was performed centrally at the Institute of Pathological Anatomy of Catholic University of the Sacred Heart. RAS and BRAF mutational genetic analyses and mismatch repair system (MMR) status evaluation by immunohistochemistry (IHC) were also performed. The trial was approved by the Ethics Committee of Catholic University of the Sacred Heart Rome and by the Institutional Review Board of each participating centre. All patients provided written informed consent before study entry and any protocol-specific procedure.

Study design, treatment and evaluations. This was a multicentre, single-arm, phase 2 trial (EudraCT number: 2012-002766-13), evaluating activity and safety of TMZ in patients with MGMTmethylated mCRC who have failed all standard therapeutic options.

Enrolled patients received TMZ (TEVA) orally under fasting conditions once a day for five consecutive days every 28 days. At each cycle, treatment was administered if ANC and platelet count were $\geqslant 1.5 \times 10^{9} / 1$ and $\geqslant 100 \times 10^{9} / 1$, respectively. Temozolomide was administered at a dose of $150 \mathrm{mg} \mathrm{m}^{-2}$ per day for the first cycle (level 0). If no grade 3-4 neutropenia, thrombocytopenia and non-haematological adverse events (AEs) (except from nausea and vomiting) occurred, the dose was increased to $200 \mathrm{mg} \mathrm{m}^{-2}$ per day starting from the next cycle (level 1). In case of grade 3 or 4 toxicity with the exception of nausea and vomiting, two dose reductions were allowed up to $100 \mathrm{mg} \mathrm{m}^{-2}$ per day (level - 1). If further toxicity occurred, patients were discontinued from treatment. Treatment was continued until occurrence of PD, unacceptable toxicity, death or withdrawal of consent.

Pre-treatment evaluation were performed within 28 days before starting treatment and consisted of: collection of tumour tissue samples (blocks or slides from primary tumours or metastases) and assessment of MGMT methylation status by MS-PCR, RAS and $B R A F$ mutational status and MMR expression status, medical history, ECOG PS, physical examination, routine haematology, biochemistry and urine analyses, electrocardiogram and contrastenhanced computed tomography (CT) scans or magnetic resonance imaging of the chest and abdomen. On day 1 of each cycle, treatment compliance, concomitant medications, symptoms, physical examination, vital signs, PS and all AEs, graded according to the National Cancer Institute Common Toxicity Criteria for Adverse Events (NCI-CTCAE) v.4.03, were recorded. Complete blood count and serum chemistry were obtained every month before each cycle. Radiographic assessment of tumour response was carried out every 8 weeks according to RECIST v.1.1 (Eisenhauer et al, 2009) until PD or consent withdrawal for any reason.

Study end points and statistical analysis. The primary end point was overall response rate (ORR), defined as the proportion of 
patients that achieved a confirmed complete response (CR) or a partial response (PR) as best response. Secondary end points were: disease control rate (DCR), defined as the proportion of patients that achieved CR, PR or stable disease (SD), duration of response (DoR), defined as the time from first documented response to the date of PD or death due to any cause, whichever occurred first; progression-free survival (PFS), defined as the time from the start of the treatment to the date of the first documented PD or death due to any cause, whichever occurred first; overall survival (OS), defined as the time from the start of the treatment to the date of death due to any cause, or censored at the date of last follow-up for alive patients; safety profile. Preplanned exploratory analyses evaluated the correlation between ORR and RAS and BRAF mutational status. All assessments were conducted on the intentto-treat population (ITT). The Kaplan-Meier method was used to estimate DoR, OS and PFS. Median values are presented with 95\% confidence interval (CI). The correlation between ORR and mutational status was assessed by two-tailed Fisher's exact test. Adverse events are presented according to NCI-CTCAE v.4.03.

This study was planned according to a two-stage Simon's optimal design (Simon, 1989; Jung et al, 2008). The null hypothesis that the true response rate is $\leq 5 \%\left(p_{0}\right)$ was tested against a onesided alternative that the response rate is $\geq 20 \%\left(p_{1}\right)$. According to this design, in the first stage, 21 patients $\left(n_{1}\right)$ were accrued: if 1 or fewer responses $\left(r_{1}\right)$ were observed in this cohort of patients, the study would be stopped early for futility; otherwise, 20 additional patients would be accrued for a total of 41 patients $(n)$. The null hypothesis would be rejected if more than four responses $\left(r_{2}\right)$ were observed in 41 patients $(n)$. Thus, if four or fewer responses would be observed by the end of stage 2, then no further investigation would be warranted. This design yields a type I error rate of $5 \%$ and power of $90 \%$ when the true response rate is $20 \%$.

Data were analysed using IBM SPSS Statistics version 22 software (IBM, Armonk, NY, USA).

Assessment of MGMT gene promoter methylation with MSPCR. After DNA modification with Methylamp DNA Modification Kit (Epigentek, Farmingdale, NY, USA), MS-PCR for MGMT were determined as described previously (Martini et al, 2008). Briefly, bisulphite-modified DNA (100-200 ng) was amplified in a mixture containing $1 \times$ PCR buffer $(20 \mathrm{~mm}$ Tris $(\mathrm{pH} 8.3), 50 \mathrm{~mm}$ $\left.\mathrm{KCl}, 1.5 \mathrm{mM} \mathrm{MgCl}_{2}\right)$, deoxynucleotide triphosphates $(0.2 \mathrm{mM}$ each), primers (20 pM each) and $0.75 \mathrm{U}$ GoTaq Hot Start polymerase (Promega, Madison, WI, USA) in a final volume of $25 \mu \mathrm{l}$. Polymerase chain reaction conditions were: an initial denaturation of $95^{\circ} \mathrm{C}$ for $8 \mathrm{~min}$, followed by 35 cycles of $95^{\circ} \mathrm{C}$ for $60 \mathrm{~s}, 60^{\circ} \mathrm{C}$ for $60 \mathrm{~s}$ and $72{ }^{\circ} \mathrm{C}$ for $60 \mathrm{~s}$. Polymerase chain reaction products were electrophoresed in a $2.5 \%$ agarose gel, stained with ethidium bromide and visualised under ultraviolet illumination. Methylation-specific-PCR analysis was performed in duplicate for all samples. Normal lymphocyte DNA supermethylated with SssI methyltransferase (New England Biolabs, Beverly, MA, USA) and treated with bisulphite was used as the unmethylated and methylated control, water as a negative control and untreated DNA as an internal PCR control. We also carried out MS-PCR on granulocyte DNA obtained from 10 healthy individuals, as the control group.

Assessment of RAS and BRAF mutational status. DNA was extracted from three $10 \mu \mathrm{m}$ slides from paraffin-embedded tissues using QIAamp DNA Mini Kit (Qiagen, Milan, Italy), following the manufacturer's protocol. KRAS and NRAS gene (2, 3 and 4 exons) and $B R A F$ gene (11 and 15 exons) were amplified using the same primers and PCR conditions described previously (Basso et al, 2013). Briefly, DNA (100-200 ng) was amplified in a mixture containing $1 \times$ PCR buffer $(20 \mathrm{~mm}$ Tris, $\mathrm{pH} 8.3,50 \mathrm{mM} \mathrm{KCl}$, $1.5 \mathrm{mM} \mathrm{MgCl}_{2}$ ), deoxyribonucleotide triphosphates (200 mM each), primers (20 pM each) and $0.5 \mathrm{U}$ GoTaq (Promega, Milan, Italy) in a final volume of $25 \mu \mathrm{l}$. After visualisation onto agarose gel, stained with ethidium bromide and visualised under UV light, PCR products were treated with ExoSAP-IT (GE Healthcare, Milan, Italy) following the manufacturer's protocol, amplified with the BigDye Terminator Cycle-Sequencing Kit (version 3.1; Applied Biosystems, Milan, Italy) using forward and reverse primers, and sequenced with an ABI PRISM 3100-Avant Genetic Analyser (Applied Biosystems). Water was used as a negative control. The sensitivity of this method is $15 \%$ in our laboratory.

Assessment of MMR expression status. Mismatch repair system analysis was performed on formalin-fixed paraffin-embedded (FFPE) tissue with antibodies against proteins MLH1, MSH2, MSH6 and PMS2. Briefly, FFPE sections ( $4 \mu \mathrm{m}$ thick) were mounted on positive charged glass slides. For antigen retrieval, deparaffinised and rehydrated sections were treated with citric acid buffer ( $\mathrm{pH}$ 6.0), two cycles of $3 \mathrm{~min}$ each at $500 \mathrm{~W}$, followed by inhibition of endogenous peroxidase with $3 \% \mathrm{H}_{2} \mathrm{O}_{2}$ for $5 \mathrm{~min}$. Then, the sections were incubated for $1 \mathrm{~h}$ at room temperature with mouse monoclonal anti-MLH-1, anti-MSH2 and anti-MSH6 (clone M1; clone G219-1129; clone 44; Roche, Monza, Italy) and mouse monoclonal anti-human PMS2 (clone 2G5; Novus Biologicals, Milan, Italy). The primary antibodies were visualised using the avidin-biotin-peroxidase complex. 3,3'-Diaminobenzidine was used as the enzyme substrate to observe the specific antibody localisation and Mayer haematoxylin was used as a nuclear counterstain. Samples were stained more than once, and the results were highly reproducible. Staining patterns of MMR proteins were evaluated using normal epithelial, stromal or inflammatory cells, or centres of lymphoid follicles as internal controls. Stained slides were scored as positive when showing nuclear staining in at least some tumour cells $(>0 \%)$.

\section{RESULTS}

Patients characteristics. Between July 2012 and June 2016, a total of 225 patients were screened. Archival tissue samples collected from each patient were assessed for MGMT promoter methylation: 80 samples (35\%) resulted positive, whereas 134 were negative and 11 did not provide adequate quality/quantity DNA to perform the evaluation. Among the 80 patients with MGMT promoter methylation, 41 met all the inclusion criteria, were enrolled in the study and received study treatment (ITT population) (Figure 1). The remaining MGMT methylated patients resulted ineligible due to: hepatic impairment (51\%), worsening of clinical condition with increase of the ECOG PS $>3$ and reduction of life expectancy to $<3$ months (41\%) and absence of adequate bone marrow function due to persistence of AEs of previous treatments $(8 \%)$.

Baseline patient and disease characteristics are summarised in Table 1. Twenty-four patients (58.5\%) were female and 17 (41.5\%) male. Median age was 66 years (range 47-81). Eastern Cooperative Oncology Group PS was 0 for 12 (29\%) patients, 1 for 23 (56\%) patients and 2 for $6(15 \%)$ patients. Primary tumour location was rectum in $6(15 \%)$, left colon in $27(67.5 \%)$ and right colon in 7 (17.5\%) patients. The median number of metastatic sites was 3. Six (15\%) patients had only one site involved and 14 (34\%) had more than three metastatic sites. The median number of previous treatment lines was 3 . Ten (24\%) patients received more than three lines and $3(7 \%)$ were previously treated with regorafenib. Twentythree $(63 \%)$ tumours were RAS mutant (MT), 2 (5\%) were BRAF MT and 13 (32\%) were RAS/BRAF WT. Only one tumour $(2.5 \%)$ presented a deficient MMR, because of the lack of MLH1 expression.

Outcome. A total of 109 cycles were administered and patients received a median of three cycles (range, 1-8). Temozolomide 


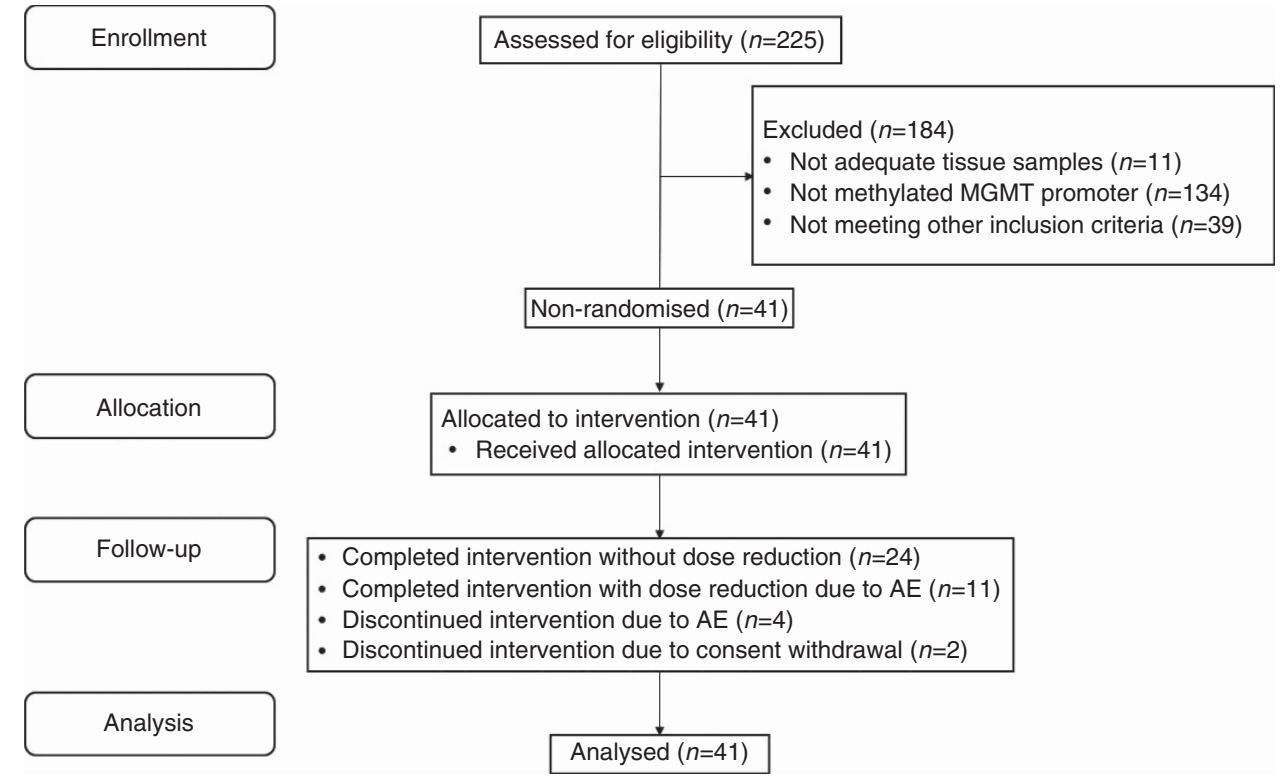

Figure 1. Study flowchart.

activity was evaluated in the ITT population and is summarised in Table 2. Overall response rate was $10 \%$ with no CR and $4(10 \%)$ PR. Stable disease was achieved in $9(22 \%)$ patients, accounting for a DCR of $32 \%$. Twenty-eight (68\%) patients experienced PD as best response (Figure 2). Thus, the primary end point of the study was not met, not reaching the prespecified level for promising activity. The DoR was 3.05 months (range, 2-6).

At a median follow-up time of 9 months, all patients experienced PD and 36 (88\%) patients died due to CRC. Kaplan-Meier curves for PFS and OS are reported in Figure 3a and $b$ respectively. The median PFS was 1.9 months (95\% CI: 1.62.35) (Figure 3a) and the median OS (Figure 3b) was 5.1 months (95\% CI: 3.9-6.2). The median PFS was significantly higher for patients achieving $\mathrm{PR}$ or $\mathrm{SD}$ as compared with patients who experienced PD (4.7 vs 1.7 months; $P<0.001)$. No significant difference was observed between patients achieving PR or SD and those with $\mathrm{PD}$ in terms of median OS (9.8 vs 6.4 months; $P=0.245)$.

All patients who had a PR were RAS MT (three KRAS MT and one NRAS MT). Of the nine patients who presented SD as best response, six had a RAS MT tumour (five KRAS and one NRAS) and three a RAS/BRAF WT tumour. Among the 28 patients who experienced PD, 16 tumours were RAS MT (15 KRAS and 1 NRAS), 2 BRAF MT and 10 RAS/BRAF WT. Therefore, with regard to the exploratory analysis, no significant correlation between $R A S /$ $B R A F$ mutational status and RR $\left(\chi^{2}\right.$ test $\left.P=0.49\right)$ or survival (PFS $P=0.967$; OS $P=0.912)$ was observed.

The only patient with MMR-deficient tumour achieved PD as best response; the PFS and OS reached by this patient were 1.7 and 29.7 months, respectively.

Overall, 20 patients (49\%) received poststudy therapy. Chemotherapy rechallenge was administered in $10(24 \%)$ patients, regorafenib in $6(14.6 \%)$, capecitabine monotherapy in $4(10 \%)$, mitomycin C in 2 (5\%) and hepatic intra-arterial injection of irinotecan-eluting bead (DEBIRI) plus systemic capecitabine in 2 (5\%).

Safety. All patients received at least one cycle of treatment and formed the safety population. Overall, 109 cycles were administered. Treatment-related AEs are summarised in Table 3. Any-grade AEs were reported in 31 patients (75.6\%). The most frequent haematological $\mathrm{AE}$ was platelet count decreased, reported in 16 patients $(39 \%) ; 13$ cases of anaemia $(31.7 \%)$ and 3 cases
(7.3\%) of ANC decreased occurred. Two patients received blood transfusion, whereas colony-stimulating factors were never required. Regarding non-haematological AEs, nausea was observed in $23(56.1 \%)$ patients, vomiting in $15(36.5 \%)$, constipation in 10 (24.4\%), liver enzyme increased in $22(53.6 \%)$ and fatigue in 4 (9.7\%). Most AEs were grade 1 or 2 (84\%). Grade 4 AEs occurred in $6(14.6 \%)$ patients. Overall, dose reduction was required in 11 (27\%). All patients discontinued study treatment; the primary reason for discontinuation was PD (35 patients; 85\%), whereas 4 (10\%) patients discontinued due to $\mathrm{AE}$ and 2 (5\%) patients withdrawn the consent. No serious AEs nor toxic deaths were recorded.

\section{DISCUSSION}

Nowadays, research is actively committed in the identification of treatment options for refractory mCRC after failure of standard therapy. The unresolved issue is the absence of effective drugs that could be offered to patients progressing after all approved treatment but still in adequate clinical conditions to face further therapy. Given the known role of MGMT promoter methylation status as predictive biomarker of response to TMZ in glioblastoma (Esteller and Herman, 2004; Heigi et al, 2005; van Nifterik et al, 2010), the high frequency of this epigenetic alteration in CRC cancerogenesis (Dunn et al, 2009) and the preliminary evidence (both from in vitro studies and clinical reports) of TMZ activity in MGMT-methylated mCRC (Raymond et al, 1997; ShachamShmueli et al, 2011, Inno et al, 2014), we hypothesised that TMZ might represent a treatment option in pretreated mCRC selected according to MGMT promoter methylation status. Thus, we conducted this phase 2 study to assess the activity and safety of TMZ in refractory $\mathrm{mCRC}$ harbouring MGMT promoter methylation.

In the present study, TMZ showed some activity, with an ORR of $10 \%$. However, the primary end point of the study was not met since the prespecified threshold for activity was not reached. In fact, we observed $4 \mathrm{PR}$ among 41 patients, while at least five responses should have been observed according to the study protocol for considering TMZ worthy of further evaluation in this setting. 


\begin{tabular}{|c|c|c|}
\hline & No. & $\%$ \\
\hline Patients & 41 & \\
\hline Median age (years) & 66 & \\
\hline $\begin{array}{l}\text { Gender } \\
\text { Male } \\
\text { Female }\end{array}$ & $\begin{array}{l}17 \\
24\end{array}$ & $\begin{array}{l}41.5 \\
58.5\end{array}$ \\
\hline $\begin{array}{l}\text { PS (ECOG) } \\
0 \\
1 \\
2\end{array}$ & $\begin{array}{r}12 \\
23 \\
6\end{array}$ & $\begin{array}{l}29 \\
56 \\
15\end{array}$ \\
\hline $\begin{array}{l}\text { Primary tumour location } \\
\text { Right colon } \\
\text { Left colon } \\
\text { Rectum }\end{array}$ & $\begin{array}{r}7 \\
27 \\
6\end{array}$ & $\begin{array}{l}17.5 \\
67.5 \\
15\end{array}$ \\
\hline $\begin{array}{l}\text { Number of metastatic sites } \\
1 \\
2 \\
3 \\
>3\end{array}$ & $\begin{array}{r}6 \\
9 \\
12 \\
14\end{array}$ & $\begin{array}{l}15 \\
22 \\
29 \\
34\end{array}$ \\
\hline $\begin{array}{l}\text { Peritoneal carcinomatosis } \\
\text { Yes } \\
\text { No }\end{array}$ & $\begin{array}{l}15 \\
26\end{array}$ & $\begin{array}{l}37 \\
63\end{array}$ \\
\hline $\begin{array}{l}\text { Liver metastases } \\
\text { Yes } \\
\text { No }\end{array}$ & $\begin{array}{l}30 \\
11\end{array}$ & $\begin{array}{l}73 \\
27\end{array}$ \\
\hline $\begin{array}{l}\text { Prior adjuvant chemotherapy } \\
\text { Yes } \\
\text { No }\end{array}$ & $\begin{array}{l}10 \\
31\end{array}$ & $\begin{array}{l}24 \\
76\end{array}$ \\
\hline $\begin{array}{l}\text { Number of treatment lines for } \\
\text { advanced disease } \\
2 \\
3 \\
>3\end{array}$ & $\begin{array}{l}15 \\
16 \\
10\end{array}$ & $\begin{array}{l}37 \\
39 \\
24\end{array}$ \\
\hline $\begin{array}{l}\text { RAS-BRAF status } \\
\text { KRAS-mutated } \\
\text { NRAS-mutated } \\
\text { BRAF-mutated } \\
\text { All genes wild type }\end{array}$ & $\begin{array}{r}23 \\
3 \\
2 \\
13\end{array}$ & $\begin{array}{r}56 \\
7 \\
5 \\
32\end{array}$ \\
\hline $\begin{array}{l}\text { MMR status } \\
\text { MMR-deficient } \\
\text { MMR-proficient }\end{array}$ & $\begin{array}{r}1 \\
40\end{array}$ & $\begin{array}{r}2.5 \\
97.5\end{array}$ \\
\hline
\end{tabular}

While the trial was still ongoing, four similar phase 2 studies on patients with MGMT-methylated refractory mCRC were published, with conflicting results (Hochhauser et al, 2013; Pietrantonio et al, 2014, 2016; Amatu et al, 2016). Hochhauser et al (2013) reported a disappointing RR of $3 \%$ among 31 patients treated with a 7-day-on/7-day-off schedule for each 28-day cycle. Similarly, Amatu et al (2016) failed to demonstrate a meaningful activity of TMZ, reporting a PFS rate at 12 weeks of $10.3 \%$ for 29 patients treated with a standard schedule of TMZ (200 mg m ${ }^{-2}$ on days $1-5$ of 28 -day cycles). In contrast, Pietrantonio et al $(2014,2016)$ observed a promising activity of TMZ in this setting, reporting a RR of $12 \%$ among 32 patients receiving the standard schedule $\left(150 \mathrm{mg} \mathrm{m}^{-2}\right.$ on days $1-5$ of 28 -day cycles) and of $16 \%$ among 32 patients treated with a dose-dense schedule ( $75 \mathrm{mg} \mathrm{m}^{-2}$ on days $1-21$ of 28 -day cycles).

Interestingly, the observed RR in the present study (10\%) and median survival times (median PFS and OS of 1.9 and 5.1 months, respectively) are consistent with those reported by Pietrantonio et al $(2014,2016)$, and somewhat comparable to those achieved by regorafenib (Grothey et al, 2013) or TAS-102 (Mayer et al, 2015) in randomised phase 3 trials. Furthermore, in our study TMZ was
Table 2. Efficacy results according to RECIST 1.1

\begin{tabular}{|c|c|}
\hline Response end point & $N(\%)$ \\
\hline ORR & $4(10)$ \\
\hline CR & 0 \\
\hline PR & $4(10)$ \\
\hline SD & $9(22)$ \\
\hline PD & $28(68)$ \\
\hline DCR & $13(32)$ \\
\hline Survival end point & Months $(95 \% \mathrm{Cl})$ \\
\hline DoR & $3.05(2-6)$ \\
\hline PFS & $1.9(1.6-2.35)$ \\
\hline OS & $5.1(3.9-6.2)$ \\
\hline \multicolumn{2}{|c|}{$\begin{array}{l}\text { Abbreviations: } \mathrm{Cl}=\text { confidence interval; } \mathrm{CR}=\text { complete response; } \mathrm{DCR}=\text { disease control } \\
\text { rate; DoR=duration of response; } \mathrm{ORR}=\text { overall response rate; } \mathrm{OS}=\text { overall survival; } \\
\mathrm{PFS}=\text { progression-free survival; } \mathrm{PD}=\text { progressive disease; } \mathrm{PR}=\text { partial response; } \\
\mathrm{RECIST}=\text { Response Evaluation Criteria in Solid Tumours; } \mathrm{SD}=\text { stable disease. }\end{array}$} \\
\hline
\end{tabular}

well tolerated with an acceptable toxicity profile, consisting mostly of grade 1 or 2 AEs (84\%).

Taken together, these data suggest that TMZ has activity against $M G M T$-methylated mCRC, but probably further investigation of other possible predictive biomarkers may contribute to select truly responsive patients leading to better results. A proposed biomarker is the mutational status of $R A S / B R A F$ genes. In fact, in their study with standard schedule of TMZ, Pietrantonio et al (2014) observed objective responses only in $R A S / B R A F$ WT patients. It was therefore postulated that RAS mutations could enhance MGMT transduction through hyperactivation of the MAPK pathway, leading to a MGMT-mediated resistance to TMZ. On the contrary, when TMZ was given with a dose-dense schedule (Pietrantonio et al, 2016), the authors observed responses exclusively in $R A S$ - or $B R A F$-mutated patients, speculating that a dose-dense schedule could enhance sensitivity to TMZ in RAS-mutated mCRC as a result of MGMT depletion due to cumulative dose and protracted drug exposure. In our study, we did not observe a significant difference in terms of TMZ activity among RAS MT and WT patients. Moreover, all patients who experienced an objective response had RAS MT tumours (three KRAS and one NRAS). This observation is in contrast with the hypothesis that RAS mutations are responsible for resistance to TMZ. Therefore, data on the role of RAS/BRAF mutational status as a biomarker of TMZ activity, as well as data on a possible correlation of the schedule with TMZ activity according to $R A S / B R A F$ mutational status, are not conclusive. Another suggested biomarker is the MMR pathway status, on whose integrity could rely the mechanism of cell death induced by TMZ (Inno et al, 2014). The study by Hochhauser et al (2013) suggested that a proficient MMR seems to be required to achieve the therapeutic effects of TMZ. Indeed, all patients achieving a PR as best response were MMR-proficient and most patients with an SD or PD were MMR-deficient. However, given the low number of PR no inference could be drawn by the authors. Moreover, the absence of MMR-deficient tumours in the studies by Pietrantonio et al (2014, 2016) and the low frequency in our cohort do not allow to identify a correlation between MMR status and response to TMZ.

Preclinical models suggest other possible mechanisms of resistance to TMZ, including the base excision repair enzyme alkylpurine-DNA $\mathrm{N}$-glycosylase involved in repairing N3-methyladenine and N7-methylguanine (Agnihotri et al, 2012), but its role in the clinical setting is not yet defined.

A possible limitation of our study is represented by the assessment of MGMT methylation on archival biopsies. Amatu et al (2016) reported a significant decline in MGMT methylation from archival samples compared with tumour or liquid biopsies taken at the time of therapy start. In our study, the median time 


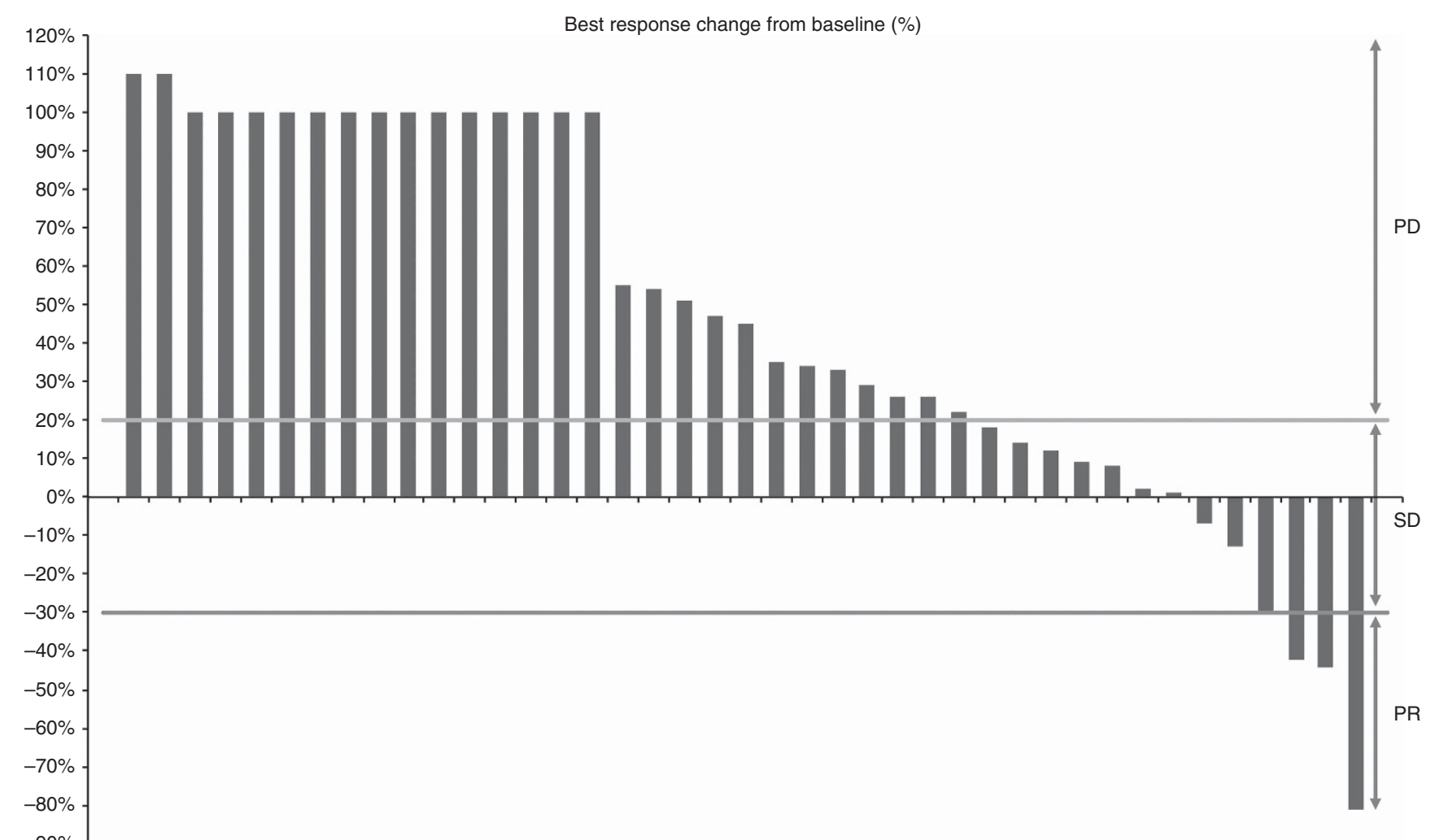

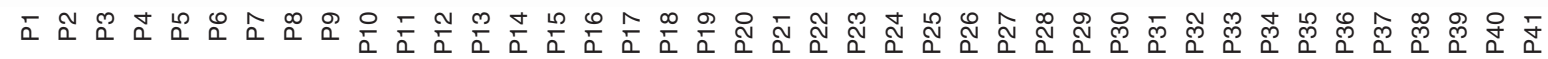

Figure 2. Waterfall plot: responses to TMZ.

A

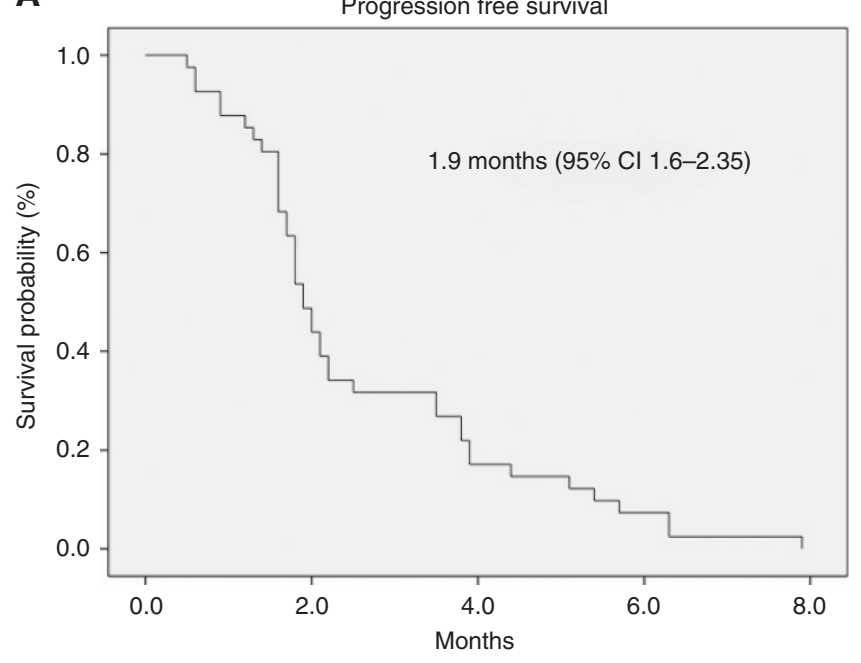

Figure 3. (A) Kaplan-Meier curve for PFS in the ITT population and (B)

from histological diagnosis on primary tumour or metastases and the start of TMZ treatment was 3 years (range $1-7,4$ years). Thus, given the dynamic epigenetic nature of this biomarker, during the long interval between tumour biopsy and start of TMZ and under the selective pressure of previous lines of therapy, MGMT methylation might have been lost in an unpredictable percentage of patients, leading to a lower than expected RR in our study. On the other hand, a long-term storage of paraffin-embedded samples could cause a reduction in MGMT methylation status, lowering the sensitivity of MS-PCR (Kalmár et al, 2015).

Another limit might be related to the assay used to perform molecular selection of patients in this setting. Sartore-Bianchi et al
B

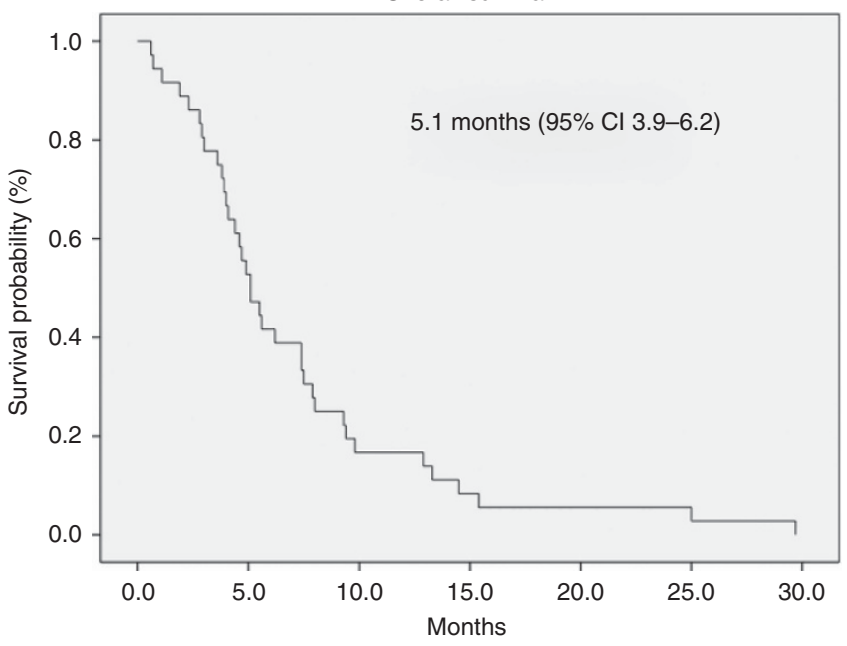

B) Kaplan-Meier curve for OS in the ITT population.

(2017) recently conducted a pooled retrospective analysis on MSPCR (MSP)-positive tumour samples from 105 patients treated within four phase 2 studies on alkylating agents (TMZ or dacarbazine) (Amatu et al, 2013, 2016; Pietrantonio et al, 2014, 2016). This analysis assessed MGMT expression by IHC and digital PCR methylation assay (methyl-BEAMing, MB) and evaluated the association with clinical outcome, identifying a subgroup of patients with a combined IHC low score/MB high level displaying a significant reduction in the hazards of progression and death. The authors showed that selection for MGMT deficiency by MSP might not be sufficient to achieve the best efficacy of alkylating treatment, whereas a combination of IHC and MB testing could 
Table 3. Treatment-related AEs according to NCl-CTCAE v.4.03

\begin{tabular}{|c|c|c|c|c|c|}
\hline \multirow[b]{2}{*}{ Adverse event } & \multicolumn{5}{|c|}{ Patients, $n(\%)$} \\
\hline & $\begin{array}{c}\text { All } \\
\text { grades }\end{array}$ & G1 & G2 & G3 & G4 \\
\hline \multicolumn{6}{|c|}{ Blood and lymphatic system disorders } \\
\hline Anaemia & $13(31.7)$ & $6(14.6)$ & $5(12.2)$ & $2(4.9)$ & \\
\hline \multicolumn{6}{|c|}{ Gastrointestinal disorders } \\
\hline Constipation & $10(24.4)$ & $5(12.2)$ & $1(2.4)$ & $1(2.4)$ & $3(7.3)$ \\
\hline Diarrhoea & $2(4.9)$ & $1(2.4)$ & $1(2.4)$ & & \\
\hline Mucositis & $3(7.3)$ & $3(7.3)$ & & & \\
\hline Nausea & $23(56.1)$ & $9(22)$ & $13(31.7)$ & $1(2.4)$ & \\
\hline Vomiting & $15(36.5)$ & $6(14.6)$ & $8(12.5)$ & $1(2.4)$ & \\
\hline \multicolumn{6}{|c|}{ General disorders } \\
\hline Fatigue & $4(9.7)$ & & $4(9.7)$ & & \\
\hline \multicolumn{6}{|l|}{ Investigations } \\
\hline Bilirubin increased & $4(9.7)$ & $2(4.9)$ & $1(2.4)$ & $1(2.4)$ & \\
\hline AST increased & $2(4.9)$ & $2(4.9)$ & & & \\
\hline ALT increased & $3(7.3)$ & $3(7.3)$ & & & \\
\hline ALP increased & $6(14.6)$ & $4(9.7)$ & $2(4.9)$ & & \\
\hline GGT increased & $7(17)$ & $4(9.7)$ & $1(2.4)$ & $1(2.4)$ & $1(2.4)$ \\
\hline Neutropenia & $3(7.3)$ & $1(2.4)$ & & & $2(4.9)$ \\
\hline Thrombocytopenia & $16(39)$ & $7(17)$ & $4(9.7)$ & $3(7.3)$ & $2(4.9)$ \\
\hline \multicolumn{6}{|c|}{ Metabolism and nutrition disorders } \\
\hline Anorexia & $2(4.9)$ & & $2(4.9)$ & & \\
\hline $\begin{array}{l}\text { Abbreviations: } A L P=a \\
\text { aminotransferase; GGT } \\
\text { Common Toxicity Crite }\end{array}$ & line phosph & ase; $A L T=$ & anine transam & $\begin{array}{l}\text { nase; AST } \\
\text { onal Cand }\end{array}$ & $\begin{array}{l}\text { aspartate } \\
\text { Institute }\end{array}$ \\
\hline
\end{tabular}

enhance patient selection in this setting. Based on these results, future prospective trials could require an optimised molecular selection with combined techniques.

In conclusion, in the present study, TMZ achieved an RR of $10 \%$ in heavily pretreated patients with MGMT-methylated mCRC, not reaching the prespecified threshold of activity. However, taking into account the evidence from other similar studies and also the possible unreliability of the assessment of MGMT methylation in archival samples, a role of TMZ in mCRC cannot be definitively excluded. Future research should elucidate the appropriate timing of MGMT methylation assessment as well as the mechanisms of primary resistance to TMZ, to enhance TMZ activity by identifying responsive patients. Therefore, when planning future trials with TMZ in mCRC, a liquid or tissue biopsy at the moment of starting therapy and a wide panel of potential biomarkers should be considered. Moreover, as MGMT methylation is an early event of CRC tumourigenesis that could be lost over time, the activity of TMZ may be higher in earlier lines of treatment than in subsequent lines. In this regard, a randomised phase 2 trial comparing $1: 1$ TMZ plus capecitabine (CAPTEM) vs FOLFIRI in patients with MGMT-methylated, RAS-mutated mCRC after failure of prior first-line oxaliplatin-based treatment is currently ongoing (Berenato et al, 2016).

CONFLICT OF INTEREST

The authors declare no conflict of interest.

\section{REFERENCES}

Agnihotri S, Gajadhar AS, Ternamian C, Gorlia T, Diefes KL, Mischel PS, Kelly J, McGown G, Thorncroft M, Carlson BL, Sarkaria JN, Margison GP Aldape K, Hawkins C, Hegi M, Guha A (2012) Alkylpurine-DNA-Nglycosylase confers resistance to temozolomide in xenograft models of glioblastoma multiforme and is associated with poor survival in patients. J Clin Invest 122(1): 253-266.

Amatu A, Barault L, Moutinho C, Cassingena A, Bencardino K, Ghezzi S, Palmeri L, Bonazzina E, Tosi F, Ricotta R, Cipani T, Crivori P, Gatto R, Chirico G, Marrapese G, Truini M, Bardelli A, Esteller M, Di Nicolantonio F, Sartore-Bianchi A, Siena S (2016) Tumor MGMT promoter hypermethylation changes over time limit temozolomide efficacy in a phase II trial for metastatic colorectal cancer. Ann Oncol 27(6): 1062-1067.

Amatu A, Sartore-Bianchi A, Moutinho C, Belotti A, Bencardino K, Chirico G, Cassingena A, Rusconi F, Esposito A, Nichelatti M, Esteller M, Siena S (2013) Promoter CpG island hyper-methylation of the DNA repair enzyme MGMT predicts clinical response to dacarbazine in a phase II study for metastatic colorectal cancer. Clin Cancer Res 19(8): 2265-2272.

Basso M, Strippoli A, Orlandi A, Martini M, Calegari MA, Schinzari G, Di Salvatore M, Cenci T, Cassano A, Larocca LM, Barone C (2013) KRAS mutational status affects oxaliplatin-based chemotherapy independently from basal mRNA ERCC-1 expression in metastatic colorectal cancer patients. Br J Cancer 108(1): 115-120.

Berenato R, Pietrantonio F, Caporale M, Bossi I, Tomasello G, Mosconi S, Paterno E, Bozzarelli S, Longarini R, Gori S, Zaniboni A, Bertolini AS, Bergamo F, Barni S, Amatu A, Fagnani D, Zampini MG, Morano F, Di Bartolomeo M, de Braud F (2016) Open-label, randomized, multicenter, phase II trial designed to compare the efficacy of CAPTEM combination versus FOLFIRI as second line treatment in patients (pts) who have progressed on or after first-line oxaliplatin-containing chemotherapy for advanced, MGMT methylated, RAS mutated colorectal cancer (CRC). J Clin Oncol 34(Suppl): abstract TPS3635.

Chan JA, Stuart K, Earle CC, Clark JW, Bhargava P, Miksad R, Blaszkowsky L, Enzinger PC, Meyerhardt JA, Zheng H, Fuchs CS, Kulke MH (2012) Prospective study of bevacizumab plus temozolomide in patients with advanced neuroendocrine tumors. J Clin Oncol 30(24): 2963-2968.

Cremolini C, Loupakis F, Antoniotti C, Lupi C, Sensi E, Lonardi S, Mezi S, Tomasello G, Ronzoni M, Zaniboni A, Tonini G, Carlomagno C, Allegrini G, Chiara S, D’Amico M, Granetto C, Cazzaniga M, Boni L, Fontanini G, Falcone A (2015) FOLFOXIRI plus bevacizumab versus FOLFIRI plus bevacizumab as first-line treatment of patients with metastatic colorectal cancer: updated overall survival and molecular subgroup analyses of the open-label, phase 3 TRIBE study. Lancet Oncol 16(13): 1306-1315.

Douillard JY, Siena S, Cassidy J, Tabernero J, Burkes R, Barugel M, Humblet Y, Bodoky G, Cunningham D, Jassem J, Rivera F, Kocákova I, Ruff P, Błasińska-Morawiec M, Smakal M, Canon JL, Rother M, Oliner KS, Tian Y, Xu F, Sidhu R (2014) Final results from PRIME: randomized phase III study of panitumumab with FOLFOX4 for first-line treatment of metastatic colorectal cancer. Ann Oncol 25(7): 1346-1355.

Dunn J, Baborie A, Alam F, Joyce K, Moxham M, Sibson R, Crooks D, Husband D, Shenoy A, Brodbelt A, Wong H, Liloglou T, Haylock B, Walker C (2009) Extent of MGMT promoter methylation correlates with outcome in glioblastomas given temozolomide and radiotherapy. $\mathrm{Br} \mathrm{J}$ Cancer 101(1): 124-131.

Eisenhauer EA, Therasse P, Bogaerts J, Schwartz LH, Sargent D, Ford R, Dancey J, Arbuck S, Gwyther S, Mooney M, Rubinstein L, Shankar L, Dodd L, Kaplan R, Lacombe D, Verweij J (2009) New response evaluation criteria in solid tumours: revised RECIST guideline (version 1.1). Eur J Cancer 45(2): 228-247.

Esteller M, Herman JG (2004) Generating mutations but providing chemosensitivity: the role of O6-methylguanine DNA methyltransferase in human cancer. Oncogene 23(1): 1-8.

Esteller M, Toyota M, Sanchez-Cespedes M, Capella G, Peinado MA, Watkins DN, Issa JP, Sidransky D, Baylin SB, Herman JG (2000) Inactivation of the DNA repair gene O6-methylguanine-DNA methyltransferase by promoter hypermethylation is associated with $\mathrm{G}$ to A mutations in K-ras in colorectal tumorigenesis. Cancer Res 60(9): 2368-2371.

Grothey A, Van Cutsem E, Sobrero A, Siena S, Falcone A, Ychou M, Humblet Y, Bouché O, Mineur L, Barone C, Adenis A, Tabernero J, Yoshino T, Lenz HJ, Goldberg RM, Sargent DJ, Cihon F, Cupit L, Wagner A, Laurent D. CORRECT Study Group (2013) Regorafenib monotherapy for previously treated metastatic colorectal cancer (CORRECT): an international, multicentre, randomised, placebo-controlled, phase 3 trial. Lancet 381(9863): 303-312.

Hegi ME, Diserens AC, Gorlia T, Hamou MF, de Tribolet N, Weller M, Kros JM, Hainfellner JA, Mason W, Mariani L, Bromberg JE, Hau P, 
Mirimanoff RO, Cairncross JG, Janzer RC, Stupp R (2005) MGMT gene silencing and benefit from temozolomide in glioblastoma. $N$ Engl J Med 352(10): 997-1003.

Hochhauser D, Glynne-Jones R, Potter V, Grávalos C, Doyle TJ, Pathiraja K, Zhang Q, Zhang L, Sausville EA (2013) A phase II study of temozolomide in patients with advanced aerodigestive tract and colorectal cancers and methylation of the O6-methylguanine-DNA methyltransferase promoter. Mol Cancer Ther 12(5): 809-818.

Inno A, Fanetti G, Di Bartolomeo M, Gori S, Maggi C, Cirillo M, Iacovelli R, Nichetti F, Martinetti A, de Braud F, Bossi I, Pietrantonio F (2014) Role of MGMT as biomarker in colorectal cancer. World J Clin Cases 2(12): 835839.

Jung SH, Lee TY, Kim KM, George SL (2008) Admissible two-stage designs for phase II cancer clinical trials. Stat Med. 23(4): 561-569.

Kalmár A, Péterfia B, Hollósi P, Wichmann B, Bodor A, Patai ÁV, Schöller A, Krenács T, Tulassay Z, Molnár B (2015) Bisulfite-based DNA methylation analysis from recent and archived formalin-fixed, paraffin embedded colorectal tissue samples. Pathol Oncol Res 21(4): 1149-1156.

Martini M, Pallini R, Luongo G, Cenci T, Lucantoni C, Larocca LM (2008) Prognostic relevance of SOCS3 hypermethylation in patients with glioblastoma multiforme. Int J Cancer 123(12): 2955-2960.

Mayer RJ, Van Cutsem E, Falcone A, Yoshino T, Garcia-Carbonero R, Mizunuma N, Yamazaki K, Shimada Y, Tabernero J, Komatsu Y, Sobrero A, Boucher E, Peeters M, Tran B, Lenz HJ, Zaniboni A, Hochster H, Cleary JM, Prenen H, Benedetti F, Mizuguchi H, Makris L, Ito M, Ohtsu A. RECOURSE Study Group (2015) Randomized Trial of TAS-102 for refractory metastatic colorectal cancer. N Engl J Med 372(20): 1909-1919.

Middleton MR, Grob JJ, Aaronson N, Fierlbeck G, Tilgen W, Seiter S, Gore M, Aamdal S, Cebon J, Coates A, Dreno B, Henz M, Schadendorf D, Kapp A, Weiss J, Fraass U, Statkevich P, Muller M, Thatcher N (2000) Randomized phase III study of temozolomide versus dacarbazine in the treatment of patients with advanced metastatic malignant melanoma. J Clin Oncol 18(1): 158-166.

Newlands ES, Stevens MF, Wedge SR, Wheelhouse RT, Brock C (1997) Temozolomide: a review of its discovery, chemical properties, pre-clinical development and clinical trials. Cancer Treat Rev 23(1): 35-61.

Patel PM, Suciu S, Mortier L, Kruit WH, Robert C, Schadendorf D, Trefzer U, Punt CJ, Dummer R, Davidson N, Becker J, Conry R, Thompson JA, Hwu WJ, Engelen K, Agarwala SS, Keilholz U, Eggermont AM, Spatz A. EORTC Melanoma Group (2011) Extended schedule, escalated dose temozolomide versus dacarbazine in stage IV melanoma: final results of a randomised phase III study (EORTC 18032). Eur J Cancer 47(10): $1476-1483$

Pegg AE (1990) Mammalian O6-alkylguanine-DNA alkltransferase: regulation and importance in response to alkylatingcarcinogenic and therapeutic agents. Cancer Res 50(19): 6119-6129.

Pietrantonio F, de Braud F, Milione M, Maggi C, Iacovelli R, Dotti KF, Perrone F, Tamborini E, Caporale M, Berenato R, Leone G, Pellegrinelli A, Bossi I, Festinese F, Federici S, Di Bartolomeo M (2016) Dose-dense temozolomide in patients with MGMT-silenced chemorefractory colorectal cancer. Target Oncol 11(3): 337-343.

Pietrantonio F, Perrone F, de Braud F, Castano A, Maggi C, Bossi I, Gevorgyan A, Biondani P, Pacifici M, Busico A, Gariboldi M, Festinese F, Tamborini E, Di Bartolomeo M (2014) Activity of temozolomide in patients with advanced chemorefractory colorectal cancer and MGMT promoter methylation. Ann Oncol 25(2): 404-408.

Raymond E, Izbicka E, Soda H, Gerson SL, Dugan M, Von Hoff DD (1997) Activity of temozolomide against human tumor colony-forming units. Clin Cancer Res 3(10): 1769-1774.

Saltz LB, Clarke S, Díaz-Rubio E, Scheithauer W, Figer A, Wong R, Koski S, Lichinitser M, Yang TS, Rivera F, Couture F, Sirzén F, Cassidy J (2008) Bevacizumab in combination with oxaliplatin-based chemotherapy as first-line therapy in metastatic colorectal cancer: a randomized phase III study. J Clin Oncol 26(12): 2013-2019.

Sartore-Bianchi A, Pietrantonio F, Amatu A, Milione M, Cassingena A, Ghezzi S, Caporale M, Berenato R, Falcomata C, Pellegrinelli A, Bardelli A, Nichelatti M, Tosi F, De Braud F, Di Nicolantonio F, Barault L, Siena S (2017) Digital PCR assessment of MGMT promoter methylation coupled with reduced protein expression optimises prediction of response to alkylating agents in metastatic colorectal cancer patients. Eur J Cancer 71: 43-50.

Shacham-Shmueli E, Beny A, Geva R, Blachar A, Figer A, Aderka D (2011) Response to temozolomide in patients with metastatic colorectal cancer with loss of MGMT expression: a new approach in the era of personalized medicine? J Clin Oncol 29(10): e262-e265.

Simon R (1989) Optimal two-stage designs for phase II clinical trials. Control Clin Trials 10(1): 1-10.

Stupp R, Hegi ME, Mason WP, van den Bent MJ, Taphoorn MJ, Janzer RC, Ludwin SK, Allgeier A, Fisher B, Belanger K, Hau P, Brandes AA, Gijtenbeek J, Marosi C, Vecht CJ, Mokhtari K, Wesseling P, Villa S, Eisenhauer E, Gorlia T, Weller M, Lacombe D, Cairncross JG, Mirimanoff RO. European Organisation for Research and Treatment of Cancer Brain Tumour and Radiation Oncology GroupsNational Cancer Institute of Canada Clinical Trials Group (2009) Effects of radiotherapy with concomitant and adjuvant temozolomide versus radiotherapy alone on survival in glioblastoma in a randomised phase III study: 5-year analysis of the EORTC-NCIC trial. Lancet Oncol 10(5): 459-466.

Stupp R, Mason WP, van den Bent MJ, Weller M, Fisher B, Taphoorn MJ, Belanger K, Brandes AA, Marosi C, Bogdahn U, Curschmann J, Janzer RC, Ludwin SK, Gorlia T, Allgeier A, Lacombe D, Cairncross JG, Eisenhauer E, Mirimanoff RO. European Organisation for Research and Treatment of Cancer Brain Tumor and Radiotherapy GroupsNational Cancer Institute of Canada Clinical Trials Group (2005) Radiotherapy plus concomitant and adjuvant temozolomide for glioblastoma. $N$ Engl J Med 352(10): 987-996.

Tabernero J, Yoshino T, Cohn AL, Obermannova R, Bodoky G, Garcia-Carbonero R, Ciuleanu TE, Portnoy DC, Van Cutsem E, Grothey A, Prausová J, Garcia-Alfonso P, Yamazaki K, Clingan PR, Lonardi S, Kim TW, Simms L, Chang SC, Nasroulah F. RAISE Study Investigators (2015) Ramucirumab versus placebo in combination with second-line FOLFIRI in patients with metastatic colorectal carcinoma that progressed during or after first-line therapy with bevacizumab, oxaliplatin, and a fluoropyrimidine (RAISE): a randomised, double-blind, multicentre, phase 3 study. Lancet Oncol 16(5): 499-508.

Torre LA, Bray F, Siegel RL, Ferlay J, Lortet-Tieulent J, Jemal A (2015) Global Cancer Statistics, 2012. CA Cancer J Clin 65: 87-108.

Tournigand C, André T, Achille E, Lledo G, Flesh M, Mery-Mignard D, Quinaux E, Couteau C, Buyse M, Ganem G, Landi B, Colin P, Louvet C, de Gramont A (2004) FOLFIRI followed by FOLFOX6 or the reverse sequence in advanced colorectal cancer: a randomized GERCOR study J Clin Oncol 22(2): 229-237.

Van Cutsem E, Lenz HJ, Köhne CH, Heinemann V, Tejpar S, Melezínek I, Beier F, Stroh C, Rougier P, van Krieken JH, Ciardiello F (2015) Fluorouracil, leucovorin, and irinotecan plus cetuximab treatment and RAS mutations in colorectal cancer. J Clin Oncol 33(7): 692-700.

Van Cutsem E, Nordlinger B, Cervantes A. ESMO Guidelines Working Group (2010) Advanced colorectal cancer: ESMO clinical practice guidelines for treatment. Ann Oncol 21(Suppl 5): v93-v97.

Van Cutsem E, Tabernero J, Lakomy R, Prenen H, Prausová J, Macarulla T, Ruff P, van Hazel GA, Moiseyenko V, Ferry D, McKendrick J, Polikoff J, Tellier A, Castan R, Allegra C (2012) Addition of aflibercept to fluorouracil, leucovorin, and irinotecan improves survival in a phase III randomized trial in patients with metastatic colorectal cancer previously treated with an oxaliplatin-based regimen. J Clin Oncol 30(28): 3499-3506. van Nifterik KA, van den Berg J, van der Meide WF, Ameziane N, Wedekind LE, Steenbergen RD, Leenstra S, Lafleur MV, Slotman BJ, Stalpers LJ, Sminia P (2010) Absence of the MGMT protein as well as methylation of the MGMT promoter predict the sensitivity for temozolomide. Br J Cancer 103(1): 29-35.

This work is published under the standard license to publish agreement. After 12 months the work will become freely available and the license terms will switch to a Creative Commons AttributionNonCommercial-Share Alike 4.0 Unported License. 